\title{
Deliberation, Reasons, and Alternatives ${ }^{*}$ \\ Justin Snedegar
}

\author{
Forthcoming in Pacific Philosophical 2uarterly
}

\begin{abstract}
A plausible constraint on normative reasons to act is that it must make sense to use them as premises in deliberation. I argue that a central sort of deliberation-what Bratman calls partial planning-is questiondirected: it is over, and aims to resolve, deliberative questions. Whether it makes sense to use some consideration as a premise in deliberation in a case of partial planning can vary with the deliberative question at issue. I argue that the best explanation for this is that reasons are contrastive, or relativized to deliberative questions.
\end{abstract}

\section{Introduction}

Contrastivists about reasons appeal to examples like the following to argue for the view that normative reasons - the things that count in favor of acting in certain ways or having certain attitudes - are fundamentally reasons for one thing rather than another, or relative to some particular set of alternatives, instead of reasons for things simpliciter:

(I) That I'm expecting a delivery tonight is a reason to make pizza at home rather than go out for pizza.

(2) That I'm expecting a delivery tonight is not a reason to make pizza at home rather than make pasta at home.

\footnotetext{
* Thanks to audiences at KU-Leuven, Duke, University of North Carolina, University of Southern California, St Andrews, Humboldt University, and Glasgow, and to anonymous referees.

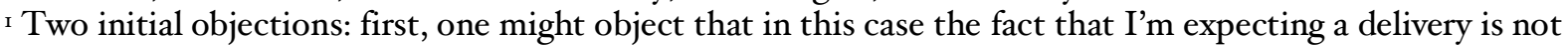
a reason to make pizza, no matter the alternatives. Rather it is a reason to be at home for the delivery. In my view it is both, but this involves the important and complicated issue of the transmission of reasons from ends to means, which I cannot address here. Note that I could have set up the case differently: it's a reason to be at home rather than go out for dinner, but not a reason to be at home rather than arrange for my neighbor to sign for the delivery. Thanks to Thomas Schmidt and Benjamin Kiesewetter here. Second, and relatedly, an anonymous referee suggests that the fact that I'm expecting a delivery is not a reason to make pizza, no matter the alternatives, but is rather a reason against going out to dinner. I think it is both, but cannot address the relationship between reasons for and against here; see Snedegar (2018). I'll just note that
} 
This example suggests that whether the fact that I'm expecting a delivery is a reason to make pizza at home depends on what we're comparing that option to. The contrastivist holds that this is precisely because reasons are contrastive: considerations are only reasons for or against options relative to certain alternatives. A reason for or against an option relative to one set of alternatives may not be a reason for or against that option relative to a different set of alternatives. This is a view about the nature of the reason relation according to which it includes an argument place for a set of alternatives. So instead of a relation like $\mathrm{R}(r, S, A)$ - 'fact $r$ is a reason for agent $S$ to perform action $A$ ' - we have a

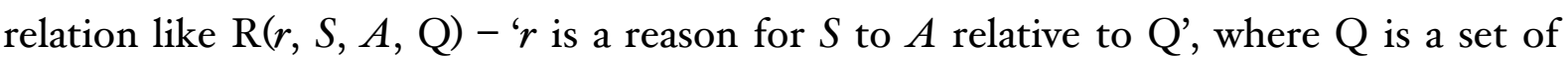
mutually exclusive alternatives, not necessarily exhaustive of all the possibilities open to the agent. ${ }^{2}$ For example, in (I) above, the set of alternatives is (make pizza at home, go out for pizza\}, while in (2) it is \{make pizza at home, make pasta at home\}.

This kind of argument relies on direct intuitions about what is and isn't a reason. I think that such claims are good starting places for arguments for contrastivism. But in this paper I develop a more theoretical argument for contrastivism, based on the role of reasons in deliberation about what to do. The idea, essentially, is that a contrastive theory of reasons best fits with the role that reasons play in deliberation. While a direct, intuitive argument like the one sketched above supports the claim that reasons are contrastive, a theoretical argument like the one I'll develop here promises to explain why reasons are contrastive.

My argument from the role of reasons in deliberation is based on a widely accepted conceptual constraint about reasons and their role in deliberation, namely that reasons must be appropriate or at least intelligible premises to use in deliberation. Following Schroeder (2007), I will call this the Deliberative Constraint. Since many philosophers accept this constraint, this argument should push them toward contrastivism. But some philosophers also reject the constraint. Naturally, this argument will not be compelling for them, though there are other kinds of theoretical arguments for contrastivism. 3

In the first section I introduce the Deliberative Constraint. I say why it is plausible, but will not attempt a full defense here. In the second section I argue that at least one central kind of deliberation, that involved in what I call, following Bratman (1987), partial planning, is question-directed: it involves trying to settle a deliberative question, understood as a set of mutually exclusive alternatives. This question-directed conception gives us an attractive way to understand the crucial features of this kind of deliberation. The third

it does seem very natural to me to weigh this fact in favor of making pizza at home, in a decision between doing that and going out for pizza. Once again, I could set up the case differently: the fact that I want something involving tomato sauce is a reason to make pizza rather than make burgers, but not a reason to make pizza rather than make pasta with tomato sauce.

2 See especially Sinnott-Armstrong (2004, 2006) and Snedegar (2013, 2017).

3 See Sinnott-Armstrong (2008) and Snedegar (2014, 20I7). 
section argues on the basis of a pair of cases of partial planning that whether some consideration is an intelligible premise to use in deliberating about whether to perform some action can vary with the particular deliberative question at issue. Given the Deliberative Constraint, this means that whether some consideration is a reason to perform the action in question can vary with the particular deliberative question at issue. In the fourth section, I argue that contrastivism gives us the best explanation of this, since according to contrastivism, reasons are relativized to deliberative questions.

To sum up, here is the argument up through the fourth section. It is worth walking through this in some detail, because the argument is a bit complex.

I. Deliberative Constraint: Reasons to do $A$ must be intelligible premises to use in deliberating about whether to do $A$.

2. The deliberation involved in partial planning is question-directed. (This conception gives us an attractive account of central features of partial planning.)

3. There are cases of partial planning in which whether some consideration is an intelligible premise to use in deliberating about whether to $A$ depends on the particular deliberative question at issue. (This question-based understanding of the cases comes from premise 2.)

4. So there are cases of partial planning in which whether some consideration is a reason to $A$ depends on the particular deliberative question at issue. (From I and 3.)

5. The best explanation of this is that the reasons involved are contrastiverelativized to deliberative questions.

6. So (via inference to the best explanation), the reasons involved in partial planning are contrastive.

If this argument is sound, then we have an important result about reasons. But this does not yet get us all the way to contrastivism about reasons, if that is understood to be the view that all reasons are contrastive. 4 If all deliberation were question-directed, then we could use the Deliberative Constraint to begin to develop an argument for contrastivism. 5 But I do not want to argue that all deliberation is question-directed. Instead, in the section 5, I briefly argue against the kind of hybrid—or, less charitably, disunified-view of normative reasons that we'd have to hold to accept the conclusion of the argument above,

\footnotetext{
4 This is how contrastivists like Sinnott-Armstrong (2008) and myself, in Snedegar (20I7), understand the view.

5 This is not to say that the claim that all deliberation is question-directed and the Deliberative Constraint together entail contrastivism about reasons, of course.
} 
but reject full-blown contrastivism about reasons, according to which some reasons are contrastive and others aren't.

\section{Reasons in Deliberation}

A widely accepted conceptual claim about normative reasons is that they must be the kind of thing that it's appropriate or at least intelligible to think about in deliberating about what to do. The idea is that our conceptual grip on reasons comes at least in part from this role that they play in reasoning: they're the things we weigh up in coming to a conclusion about what to do or what to think. Following some of the literature (see, e.g., Way (20I7)), I will call the particular way we use reasons in deliberation using as a premise. I intend 'premise' to be read so that it does not imply that the deliberation is necessarily deductive, or even that it explicitly takes the form of an argument. Rather, using a consideration as a premise in reasoning is just meant to capture the distinctive way we treat considerations as reasons in deliberating-paradigmatically, but perhaps not exclusively, weighing them up against competing considerations.

The constraint is often understood in terms of some notion of appropriateness. But for my purposes it is enough to use an even weaker notion of intelligibility; I take this to be a weaker notion since if we would approve of someone using something as a premise then surely we would also be able to make sense of her using it as a premise. There are various ways in which it might be inappropriate to use some premise in reasoning. Perhaps it only speaks in favor of some option extremely weakly, so that it would be better to just ignore it. Or perhaps it has been excluded, in Raz's (1975) sense, so that you have strong reason (due to a promise, perhaps) not to take such considerations into account in deliberating. ${ }^{6}$ It may be that the sense in which using these kinds of considerations as premises in reasoning is not inappropriate in the sense intended by advocates of the constraint, but in order to avoid having to settle on a notion of appropriateness, I will just appeal to the weaker notion of intelligibility. Even if some consideration is very weak, or has been excluded, we may be able to at least make sense of someone using it as a premise in deliberation. On the other hand, some considerations are just not intelligibly used as premises: in deliberating about whether to have the sandwich or the salad, the fact that $2+2=4$ is generally just not something that we could make sense of someone using in their deliberation. The constraint I have in mind says that such considerations just cannot be reasons bearing on whether to have the salad or the sandwich.

\footnotetext{
${ }^{6} \mathrm{~A}$ classic example is of a parent promising his partner not to take considerations of cost into account in deciding where to send their child to school. Such considerations are still reasons, but they've been excluded - the parent has strong (perhaps decisive) reason not to take them into account in deliberating, and so doing so would be inappropriate, in a good sense of 'appropriate'.
} 
More precisely, the constraint is this (borrowing the name from Schroeder (2007)):

Deliberative Constraint: If some consideration $r$ is a reason for or against doing $A$, then it would be (at least) intelligible to use $r$ as a premise in deliberating about whether to $A$, if you knew about it.

By 'deliberating about whether to $A$ ', I just mean that $A$ is one of the options over which the agent is deliberating, or trying to choose between.7 The constraint holds that if some consideration isn't an intelligible thing to use in deliberation, then it isn't a reason. This doesn't imply that everything that we intelligibly think about in deliberation is a reason. For example, Dancy (2004), Chapter 3, discusses enablers/disablers, which are conditions that must hold/not hold in order for some fact to be a reason, and attenuators/intensifiers, which modify the strength of a reason. These considerations are relevant for determining what we ought to do, and things that we often need to think about in deliberating, but part of Dancy's point is that they are not reasons. Perhaps even more obviously, the reasons for or against alternatives to $A$ will be intelligible premises in deliberating about whether to $A$, but are not necessarily reasons for or against $A$. But the Deliberative Constraint tells us that these considerations must be intelligible premises to use in deliberating about whether to perform those alternatives.

The last clause, 'if you knew about it', is important. It would not be intelligible for me to use some consideration that I don't know about-especially one I believe to be false-in deliberation. But many people think that such considerations can nevertheless be reasons, since we don't always know about all of our reasons.

Some philosophers go further and turn this kind of constraint-in particular, the stronger version involving some notion of appropriateness - into an analysis of reasons, holding, roughly, that what it is for a consideration to be a reason is to be an appropriate premise in deliberation. Similarly, Hieronymi $(2005,2013)$ holds that what it is to be a reason to $A$ is to be a consideration that bears on the question of whether to $A$. The kind of argument I give here should be especially compelling for those who accept these kinds of analyses, but for the purposes of this paper, I do not assume them. ${ }^{8}$

It is enough for me to think of the Deliberative Constraint just as a constraint on when something is a reason, and not as the basis for an analysis of reasons. Even philosophers who think of reasons primarily as normative weight contributors, rather than as premises in deliberation, can accept that they are intelligible premises in deliberation-

\footnotetext{
7 I've formulated the Deliberative Constraint in terms of deliberation about whether to $A$. In general, whether questions are yes/no questions, so asking whether to $A$ would amount to deciding whether to $A$ or not- $A$. But I have in mind deliberation that may involve consideration of more alternatives than simply $A$ and not$A$; so strictly speaking I should use the more awkward phrase, 'deliberation about what to do, where $A$ is one of the options'.

${ }^{8}$ See, for views of this sort, Williams (1979), Setiya (2014), Way (2017), Gregory (2016), and Silverstein (2016).
} 
indeed, they may be intelligible (and indeed, appropriate) premises because they contribute normative weight for or against the relevant options.

Several philosophers use this kind of constraint in arguing about reasons. For example, Williams (I979), Korsgaard (I986), and Smith (I995) all hold that reasons to $A$ must be able to at least potentially motivate you to $A$, through sound deliberation (this is what Korsgaard and Smith call the "internalist requirement"). This plausibly implies that reasons to $A$ must be intelligible premises in potential instances of deliberation concluding in $A$-ing. These philosophers make use of this constraint in arguing for particular conceptions of reasons (though of course their particular understandings of sound deliberation and the resulting views of reasons are very different). Schroeder (2007), who analyzes reasons in terms of desires rather than in terms of their role in reasoning, nevertheless appeals to this kind of constraint in developing his theory. In particular, he argues that facts about your desires themselves are at least often not reasons, since it would be objectionably self-regarding - and so not good or appropriate reasoning - to think about your desires, rather than the desired or desirable features of the object or action in question, in deliberation.9 So many philosophers with very different views of reasons accept some version of the idea that reasons must be appropriate premises in deliberation, which implies that they are also intelligible premises.

One reason to accept this kind of constraint, due to Way (2017), is that it explains what may otherwise seem to be a puzzling kind of restriction on reasons. ${ }^{\circ}$ We can have reasons for actions, beliefs, and many affective attitudes. But we cannot have reasons for lots of other states, like being six inches taller or having been born ten years earlier. ${ }^{I I}$ If we just think of reasons as considerations that "count in favor" of what they are reasons for, then this kind of restriction may seem puzzling. There are certainly things that count in favor of my being six inches taller, e.g., I'd be able to dunk a basketball. Nevertheless, this isn't a reason for me to be six inches taller. The Deliberative Constraint explains this: I can't intelligibly deliberate about whether to be six inches taller (assuming I don't have

\footnotetext{
9 The weaker version of the Deliberative Constraint appealing just to intelligibility is not sufficient for Schroeder's purposes, if it's intelligible (though inappropriate) to use facts about your desires as premises in reasoning. Nevertheless, if I'm right that appropriateness implies intelligibility, then Schroeder also accepts my weak version of the Deliberative Constraint.

ro Way uses this as an argument in favor of his analysis of reasons as premises in deliberation, but just adopting the Deliberative Constraint as a constraint is enough to secure this advantage. We may also be able to explain this restriction by adopting some version of a "reason implies can" principle (assuming that I don't have access to a time machine and am full grown). One nice thing about the explanation in terms of the Deliberative Constraint is that, if it were true, it would help explain such a principle: you can't have reasons for things you can't do, since (assuming you're aware you can't do them) you can't intelligibly deliberate about whether to do them.

II This claim is not uncontroversial. For example, Finlay (2014) holds that there can be reasons for these kinds of states. In fact I am somewhat sympathetic to Finlay's view here; the issue seems to me similar to the "ought-to-be" vs. "ought-to-do" distinction. Finlay holds the view about reasons that corresponds to the claim that the "ought-to-do" can be reduced to the "ought-to-be". See Finlay and Snedegar (2014) for a contrastivist defense of this kind of view of 'ought'; a similar defense of the corresponding view about reasons may be available, but I will leave this aside here.
} 
access to height-increasing drugs), so there cannot be intelligible premises in deliberating about whether to become six inches taller. Thus, according to the constraint, there cannot be reasons for me to be six inches taller, even though there can be considerations that count in favor of this.

So besides being widely accepted, this constraint explains an important kind of conceptual restriction on what we can have reasons for. Moreover, the constraint is, on its face, very plausible. To deny it would be to hold that there are reasons for or against our options that it would nevertheless be unintelligible for us to use in deliberating about whether to perform those options, even assuming we know about them. Nevertheless, there are objections to the constraint. ${ }^{2}$ I have certainly not given a full defense, here. But my main goal is to argue that if some version of this constraint is true-as many philosophers believe-we get an interesting argument for contrastivism.13

\section{$3 \quad$ Partial Planning and Deliberative Questions}

\section{I Partialplanning}

I assume that deliberation, at least ideally, concludes in a plan or intention about what to do. It sometimes concludes in the suspension or withbolding of plan or intention, but the aim of practical deliberation is to settle on a plan about what to do. This is analogous to the claim that the aim of theoretical reasoning is a belief. Deliberation about what to do will at least often involve weighing up reasons bearing on some options, and it concludes when you settle on one of them by forming an intention or plan.

The particular type of deliberation that I'll focus on here is what, following Bratman (I987), I'll call partial planning. As Bratman emphasizes, the plans we form as a result of deliberation are typically partial, and need to be "filled in" as the time for action approaches. For example, my deliberation about what to do for dinner may conclude in a plan to make dinner at home. But before I can carry out this plan, I need to fill it in by deciding (at least) what to make and when to make it. Note that this is not quite the same

\footnotetext{
${ }^{12}$ See Schroeder's (2007) Surprise Party case, for example. That there is a surprise party next door is a reason for you to go, but it's not one you can intelligibly use in reasoning, since if you knew about it, it would not be a reason for you to go (we can assume). Others have responded to cases like this in defense of constraints like the Deliberative Constraint (e.g., Way and Whiting (2016)). I leave this issue aside, here, though a full defense of the Deliberative Constraint would need to address it.

${ }_{13}$ Another potential complication comes from Wedgwood (2015). He argues that the two conceptions of reasons one finds in the literature-(i) as ought-explainers or weight-contributors and (ii) as premises in deliberation - cannot both be true of the same kind of thing. If that is correct, then the argument I develop here just concerns a different kind of thing than the 'reasons' that many other philosophers theorize about, and in fact a different kind of thing than other arguments for contrastivism concern (e.g., Snedegar (2OI4, 2OI7)).
} 
as saying I need to come up with a plan for carrying it out, which may involve coming up with a series of steps to take, like a recipe. Rather, the kind of filling in of the plan or intention with which I'm concerned here must be done before I can come up with a series of steps for carrying it out. We can think this as settling on a way of making dinner, like making pizza for dinner at 6:30pm.

Bratman shows why the ability to engage in this kind of partial planning-forming partial or coarse-grained plans, and then filling in the details as the time for action approaches - is very beneficial for agents like us. Deciding every detail ahead of time is cognitively demanding; partial planning allows us to distribute these demands over time. Further, partial plans can often better play the crucial role of helping us coordinate, both with others and with ourselves over time. Very detailed plans are more likely to conflict with the plans of others with whom we need to coordinate, and to rule out more combinations of plans of mine that I may want to coordinate into a larger plan. For example, my plan to drive the car to campus at 8:30am would conflict with my wife's plan to drive the car to her office at 8:30am. But a plan to go to campus tomorrow morning would not necessarily conflict with her plan, since I can just fill in the plan by deciding to take the bus. So partial, or coarse-grained, plans are less likely to need to be dropped in the face of new information, both about the world and about the plans of others. This allows them to be more stable; it is important that our plans be relatively stable, since otherwise we could not coordinate with others or with ourselves.

\subsection{Partial planning as question-directed}

My suggestion is that partial planning is question-directed, in the following sense: it at least typically involves considering and settling a series of deliberative questions, or questions of what to do. ${ }^{4}$ Here I follow Cariani (2013) in conceiving of deliberative questions as sets of mutually exclusive alternative courses of action. For example, one deliberative question may be \{go to work, go to the beach, stay home in bed\}; deliberating about what to do today would then involve considering this deliberative question with the aim of selecting one alternative. Selecting, say, going to the beach, constitutes forming a plan or intention to go to the beach. This is to model deliberative questions on an orthodox picture of ordinary questions about what's the case; it is common to think of these as sets of alternative potential answers to the question, which will be propositions. Selecting one of the answers to the question, in the ordinary, theoretical case, constitutes forming a belief in the selected proposition. ${ }^{15}$ We can think of these sets of answers alternatively (but perhaps equivalently) as partitions over parts of logical space; the aim then is to find the

\footnotetext{
I4 See Friedman (2013, forthcoming) for a discussion of question-directed attitudes, including deliberation. I5 See, for example, Hamblin (1958), Groenendijk and Stokhof (1997), Roberts (2012), and Friedman (2013, forthcoming). This is not the only conception of questions, but it is a popular one.
} 
cell of the partition containing the actual world. ${ }^{6}$ A deliberative question, by contrast, will be a partition over part of the space of possible options. Crucially for my purposes, in either case, the partitions may be more or less fine-grained. More coarse-grained ones will ignore distinctions between possibilities made by more fine-grained ones. For example, \{go out, stay home\} is more coarse-grained than go to the beach, go to the store, stay home and read, stay home and nap\}, though both are perfectly good questions to deliberate over.

So my claim is that partial planning is question-directed: in partial planning, we deliberative over a deliberative question, or set of alternatives, with the aim of selecting one alternative. The support for this conception is that it gives us attractive accounts of the two central features of partial planning: (i) the sense in which a partial plan is partial and (ii) what it is to fill in a partial plan. A (relatively) partial plan is one that answers a (relatively) coarse-grained deliberative question. Filling in a partial plan is then considering and settling more fine-grained questions about which way one will carry out the coarsegrained plan. For example, if my partner calls and asks what to do for dinner, I may consider the deliberative question, \{make dinner, go out\}. Selecting one of these-say making dinner - is forming a plan or intention to make dinner. This sets further questions, including what to make and when to make it. These questions may be, for example, \{make pizza, make pasta, make salmon\} and \{make dinner at 6pm, make dinner at 6:30pm, make dinner at $7 \mathrm{pm}$ \}. To fill in the partial plan is to answer these more fine-grained questions set by the partial plan.

Note that the deliberative questions are sets of mutually exclusive alternatives, but they need not be exhaustive of all of the possibilities. Some possible courses of action may be left out, for one reason or another. Of particular relevance is that in cases of partial planning, the deliberative question set by a partial plan, the answering of which amounts to filling in the partial plan, will not include possibilities that aren't ways of carrying out the partial plan. ${ }^{17}$

This quick sketch of the question-directed conception of partial planning is enough to let me develop the argument for contrastivism in the next section. But there are clearly many important open questions. One is what it is for a partial plan to "set" a new deliberative question. The partial plan is incomplete in various ways, and we can understand the ways in which it is incomplete in terms of further questions: when to make dinner? or what to make for dinner?, for example. But to actually get a deliberative question, we need the set of alternative answers, since on the view of deliberative questions I'm

\footnotetext{
${ }^{16}$ Note that on this view of theoretical questions, the potential answers are mutually exclusive. Some views of questions may deny this, but at least in the case of deliberative questions, it is a very natural assumption, since it's hard to make sense of trying to choose between consistent courses of action.

${ }_{17}$ Bratman (1987) argues for the importance of this filtering role of our partial plans. He also emphasizes that it is important that we are able to reconsider our plans. Reconsidering my plan to make dinner at home is not a way of answering the question, e.g., of what to make. Rather, it is plausibly to reopen the previously closed coarse-grained question, or one similar in case new options have presented themselves.
} 
adopting here, a deliberative question just is a set of alternative answers. This introduces a different sense in which a deliberative question must be set: the potential answers - the alternatives over which the agent will deliberate-must be specified. In this sense of setting a deliberative question, it is plausibly the agent who sets the question, by finding alternative potential ways of carrying out the partial plan.

In discussing partial planning, I have focused on one aspect of deliberation, namely that of weighing up reasons for and against alternatives. We've just seen a second, and plausibly in some sense prior aspect, which is finding those alternatives in the first place. Most work in practical reasoning and decision theory takes the set of alternatives as a given, and focuses on how rational agents weigh them against one another to select one. ${ }^{8} 8$ But there are also very interesting questions about this prior stage of deliberation. For example, assuming that (as limited agents) we cannot consider every possible alternative, an important question is which and how many alternatives we should consider, in a given case. Relatedly, there's a question about when it is irrational to keep searching for new alternatives, rather than just getting on with the decision. ${ }^{19}$ Plausibly these kinds of questions are themselves things we can deliberate about: \{get on with the decision, keep looking for alternatives\}, for example. Though these questions about deliberation are not the kinds of deliberative questions I'll focus on here, this is an important aspect of deliberation. Moreover, assuming that reasons also have a role to play in this aspect of deliberation, what I say about reasons should also fit with it.

Finally, it is important to emphasize that my claim is not that all deliberation is question-directed. I am not claiming that all deliberation involves explicit consideration of a well-defined set of alternatives. ${ }^{20}$ All that I am claiming, and all that I'll rely on in my argument, is that one important kind of deliberation - that involved in filling in partial plans - is question-directed. Again, the support for this claim is that this conception gives us an attractive way to understand what it is for a plan to be partial, and what it is to fill in a partial plan. My argument in the next section will be that given this question-directed view of partial planning and the Deliberative Constraint, we get support for the claim that the reasons involved in partial planning are contrastive-relativized to sets of alternatives. This does not take us all the way to full-blown contrastivism about reasons, since the argument by itself doesn't tell us anything about reasons that are not used in partial planning. I address this gap in section 5 .

\footnotetext{
${ }^{18}$ See, for example, Jeffery (I965), Chapter I and Resnik (1987), Chapter I. Also see Resnik, pp. Io-II for a brief discussion of the problem of specifying a set of options, however.

19 See, for a sampling, Smith (199I), Lin (2014), and Wedgwood (2017).

${ }^{20}$ See, for a particularly relevant example, Jordan (2013), who argues on the basis of virtuously whole-bearted action, which is undertaken with no consideration of alternatives at all, that at least some reasons (those which support such action) are not contrastive.
} 


\section{Contrastive Reasons}

\section{I Earmarks of intelligible premises}

As I explained at the beginning of this paper, direct arguments for contrastivism rely on intuitive claims about what is and is not a reason in a given case. My argument in this section, based on the Deliberative Constraint, relies on claims about what is and is not an intelligible premise in deliberation. Two earmarks of intelligible premises that I'll appeal to below are the following. First, intelligible premises in deliberation are considerations that help you answer the deliberative question you are facing. If some consideration is of no use in answering your deliberative question, and you know it, then it would not be intelligible for you to go on to use it as a premise in deliberation.

Second, intelligible premises in deliberation could in principle, depending on what other considerations are relevant, be an intelligible basis on which to settle the deliberative question. ${ }^{21}$ Perhaps we would disagree, in a given case, that the consideration is actually weighty enough, relative to the competing considerations, to fully justify the choice. But it should at least be intelligible that someone could make the choice on the basis of the consideration, even if in fact they made the wrong choice, perhaps due to being mistaken about the relative weights, about what other considerations were relevant, or just being weak-willed.

\subsection{Tro cases of partial planning}

Consider a process of partial planning. Suppose my partner calls to ask what I want to do for dinner. Deliberating about what to do for dinner can, in different contexts, correspond to many different deliberative questions; suppose that in this case it is have pizza, have Thai food, have burgers\}. I will consider various considerations in trying to settle this deliberative question. Suppose I settle this question by forming a plan to have pizza. This will then set a new deliberative question, \{make pizza, go out for pizza\}. Again, once I begin deliberating about this question, I will consider various considerations. One important one, let's suppose, is that I am expecting a delivery. It would be intelligible for me to use this as a premise in deliberating about whether to make pizza or go out for pizza. It helps me settle the deliberative question. Further, it would be intelligible for me to base a decision to make pizza at home on this consideration. Thus, it satisfies the Deliberative Constraint, and so can be a reason, in particular a reason to make pizza, in this case.

\footnotetext{
${ }^{21}$ Compare Gregory (2016), who holds that what it is to be a reason is to be a good basis.
} 
But suppose that things had gone slightly differently, and the first deliberative question I considered was not \{have pizza, have Thai food, have burgers\} but instead \{make dinner, go out\}. Suppose I settle this question by forming a plan or intention to make dinner. This will then set a new deliberative question about what to make, say, \{make pizza, make pasta, make salmon\}. In trying to settle this question, once again, I will consider various considerations. But the fact that I am expecting a delivery tonight does not satisfy the Deliberative Constraint, at this stage of deliberation. It would not be intelligible to use this consideration as a premise in deciding whether to make pizza, make pasta, or make salmon, since it doesn't in any way distinguish between them. It will not help me settle this deliberative question. It would not be intelligible to base my decision to make pizza on the fact that I'm expecting a delivery tonight, regardless of the competing considerations, so long as we hold the deliberative question fixed. By the Deliberative Constraint, then, it is not a reason, and in particular, it is not a reason to make pizza.

So whether the fact that I'm expecting a delivery tonight is an intelligible premise to use in deliberation about whether to make pizza-and given the Deliberative Constraint, whether it is a reason to make pizza-appears to depend on the particular deliberative question at issue. A straightforward explanation of this is the contrastivist one that the reason is relativized to a deliberative question, such that relative to \{make pizza, go out for pizza\}, it is a reason, while relative to \{make pizza, make pasta, make salmon\}, it isn't. Shortly I will argue that the contrastivist explanation is better than another candidate explanation for how reasons can depend on the deliberative question.

It is true that in this process of partial planning, the fact that I'm expecting a delivery will likely feature as a reason at one stage, namely the stage at which I'm deliberating about whether to make dinner or go out. Here, this fact will be a reason to make dinner. It will satisfy the Deliberative Constraint, relative to this deliberative question: it will help me answer the question, and would be an intelligible (indeed, good) basis for a decision to make dinner at home. But the important point is that when it comes to the option of making pizza, whether this fact is a reason or not depends on the particular deliberative question at issue. Note that in a different case in which I deliberate about whether to make dinner at home or order in, that I'm expecting a delivery will not be a reason to make dinner at home.22

\footnotetext{
${ }^{22}$ As I noted in footnote I, one reply to these kinds of cases is that the fact that I'm expecting a delivery isn't really a reason to make pizza, but a reason to be at home for the delivery. I will just reiterate what I said in the text: we can set up a different case in which I'm deliberating about whether to be at home for the delivery, or arrange for my partner to be at home for the delivery. In this case, that I'm expecting a delivery is not an intelligible premise, and so not a reason to be at home for the delivery. The endpoint of this line of response is to hold that there is some privileged, highly general action that this fact is a reason for. But at the very least, this seems to be in tension with the idea that this paper takes as its starting point, that an important role for reasons is to be used in deliberation, since we usually do not deliberate over such highly general options.
} 
It is easy to imagine someone offering the fact that they are expecting a delivery as their justification for making pizza at home, even if their partial planning took the same route as in the second case above. But compare two ways someone might ask why the person made pizza, using italics to signal intonational stress: (i) 'Why did you make pizza?', vs. (ii) 'Why did you make pizza?'. If the question is asked in the first way, it is natural to answer "Because I am expecting a delivery". But if asked in the second way, it is not natural to answer in this way. This provides further evidence that reasons can vary with the deliberative question at issue, because the orthodox account of intonational stress is as signaling a dimension of contrast, which gives us a set of alternatives. ${ }^{23}$ Putting stress on 'make' makes salient a set of alternative ways of getting pizza, e.g. going out for pizza. Putting stress on 'pizza', on the other hand, makes salient a set of alternative things to make, e.g. pasta or salmon. So (i) and (ii) will tend to raise different deliberative questions. This also highlights that the important thing here isn't what path the agent's deliberation happened to take. Rather, the important point, which considering different processes of partial planning helps to bring out, is that intelligible premises, and so reasons, can vary with the deliberative question at issue.

\subsection{Contrastivism as the best explanation}

Contrastivism offers a straightforward explanation for why the reasons for $\operatorname{doing} A$ would vary with the deliberative question at issue. According to contrastivism, considerations are only reasons for options relative to some deliberative question or other. So if two instances of deliberation about whether to $A$ are directed at different deliberative questions - as can happen in different instances of partial planning - then we should expect the reasons to $A$ to differ between these instances of deliberation.

Nevertheless, contrastivism is not the only explanation for why reasons for doing $A$ can vary with the deliberative question at issue. An alternative explanation for why reasons to A can vary with the deliberative question at issue is a contextualist one, according to which reasons are context-relative, and in particular relative to which plans the agent has formed. In a context in which I've already formed a plan to make dinner at home, the fact that I'm expecting a delivery is just not a reason for me to make pizza. But in a context in which I have not yet formed this plan, but only formed a plan to have pizza (one way or another), this fact is a reason for me to make pizza.

On one interpretation, this view is consistent with contrastivism. If we take this contextualist view to be a view about reason ascriptions, and in particular how to interpret claims like ' $r$ is a reason for you to A', then the contrastivist can accept it. Importantly,

${ }_{23}$ See especially Rooth (I992). For arguments for contrastivism about knowledge relying on this point, see Schaffer (2005, 2008). 
contrastivism is a view about the metaphysics or structure of the reason relation: it is the view that the relation includes an argument place for a set of alternatives, or deliberative question. A question for the contrastivist, then, is the linguistic one of how to interpret reason ascriptions which do not explicitly mention the deliberative question, e.g. through a use of 'rather than'. 24 This is important since contrastivists hold that we can only evaluate a reason ascription for truth if we specify the deliberative question. One option is the contextualist view of reason ascriptions just mentioned, according to which the deliberative question is fixed by the context, and in particular by the plans the agent has adopted. But there are other options, as well. For example, we could adopt a simple speaker contextualist view according to which the deliberative question is fixed by what the speaker has in mind.

To be a genuine competitor to contrastivism, then, the contextualist view must be a view about the structure of the reason relation that denies that it has an argument place for a set of alternatives. Moreover, though the contextualist may hold that the reason relation has an argument place for context, or circumstances, if the view is to be a genuine competitor to contrastivism, she should deny that the context is to be understood as an $n$-tuple, one of whose elements is a deliberative question (along with, e.g., time). If one of the elements of the context with which reasons can vary is a set of alternatives, then this kind of contextualism would qualify as a contrastivist view, or at least one on which reasons are deliberative question-relative. On either view, considerations are only reasons relative to a given deliberative question.

On a version of contextualism that is a genuine competitor to contrastivism, then, the agent's previously formed partial plans help determine what her reasons are, but not by setting any parameter for a deliberative question. We can make the structure of this view clearer by making this relativization to contexts, including the previous decisions, explicit: relative to the context in which I've decided to make dinner at home, the fact that I'm expecting a delivery is not a reason to make pizza at home, while relative to a context in which I have not made this decision, this fact is a reason for me to make pizza at home. It's important to remember, though, that this shift in the reasons for making pizza is not due to a shift in which alternatives are under consideration.

For this kind of contextualist, the agent's previously formed plans arguably have too much influence on what reasons there are for her to act. Even if her previous decisions are bad ones, they still determine what reasons there are for her to act now. For example, my previous decision to burn down my neighbor's house may change the context in such a way that I now have reason to soak it in kerosene. Perhaps this isn't obviously false, but the important point I want to make now is that for the contrastivist, we need not give the agent's previous decisions so much power in determining what reasons she has.

${ }_{24}$ See Sinnott-Armstrong (2006), Chapter 5, and Snedegar (2013) and (2OI7), Chapter 2 for discussion. 
For the contextualist to explain cases like the one I've focused on in this paper, she must allow the agent's previous decisions to affect what reasons the agent has, relative to the context in which she has made those decisions, but not by affecting which options are under consideration. For the contrastivist, on the other hand, what reasons there are relative to a given deliberative question need not be determined by the agent's previously formed plans.25 There is the further question of which deliberative question is the appropriate one for the agent to deliberate over in a given case, and her previous plans will very plausibly often play a role in determining this. But contrastivism can also be developed so that other factors are relevant for determining which question the agent should be deliberating over.

This discussion brings out an important point, mentioned at the end of the previous subsection. The argument is that contrastivism-a metaphysical view about the nature of reasons - offers the best explanation of a certain phenomenon, namely that which considerations it is intelligible to use as premises in deliberating about whether to $A$ can vary between different instances of deliberation, where the difference is in the deliberative questions at issue. Though I relied on cases of first-person partial planning, the important point is not that my reasons vary with my decisions. Rather, appealing to cases of partial planning is a way to make it clear that different instances of deliberation about whether to $A$ can involve different deliberative questions. I argued that when it does, what it makes sense to use as a premise in deliberation about whether to $A$ - and so, via the Deliberative Constraint, what is a reason for or against $A$ - can vary. We need an explanation for why it is intelligible to use a particular consideration as a premise in deliberating about whether to $A$ given one deliberative question, but is not intelligible to use this same consideration as a premise in deliberating about whether to $A$ given a different deliberative question. This phenomenon doesn't itself entail contrastivism, since we've seen that there is a competing contextualist explanation available. But I've just argued that contrastivism-the view that reasons are relativized to deliberative questions - offers a better explanation.

\subsection{Contrastivism and the Deliberative Constraint}

I've just argued that reasons are contrastive- that whether some consideration is a reason for or against an action depends on the particular deliberative question at issue. My argument for contrastivism turned on the Deliberative Constraint, which states that if some consideration is a reason for or against doing $\mathrm{A}$, then it is intelligible to use it as a premise in deliberating about whether to $A$. One thing the argument above brings out is

${ }^{25}$ For example, on the view I develop in Snedegar $(2014,2017)$, the reasons for $A$ relative to $\mathrm{Q}$ are determined by facts about how well $A$ promotes objectives (like objects of the agent's desires, or values like justice, honesty, and happiness), compared to the alternatives. 
that 'deliberating about whether to $A$ ' (or, more precisely, 'deliberating about what to do where $A$ is one of the options') can refer to different deliberative questions, depending (among other things) on the how the process of partial planning has gone. What I argued is that which considerations are intelligible premises can vary with the particular instance of deliberation at issue. A better version of the Deliberative Constraint will make this explicit:

Deliberative Constraint - Revised: If some consideration $r$ is a reason for or against doing $A$, in a particular instance of deliberation, then it would be intelligible to use $r$ as a premise in that instance of deliberation about whether to $A$.

So far, this does not build in contrastivist assumptions; it just accommodates the fact that when we're discussing the role of reasons in deliberation, we should recognize that the reasons may sometimes depend on the particular instance of deliberation. The argument of this section is that (i) at least one way that this can happen is for the instances of deliberation to be aimed at different deliberative questions, and (ii) contrastivism offers the best explanation of this. So the contrastivist would interpret 'in a particular instance of deliberation', in the constraint, as 'relative to a particular deliberative question'.

\section{$4.5 \quad$ Objection: Buridan cases}

The argument that whether some consideration is a reason can depend on the particular deliberative question at issue, and ultimately for contrastivism, relied on the claim that if some consideration does not distinguish between the alternatives at all, and thus does not help answer the deliberative question, then it is not an intelligible premise, and so not a reason. But this appears to be the same mistake that Buridan's Ass made: he faced two qualitatively identical bales of hay, and since (i) there was no reason to choose one over the other and (ii) being very rational, he could only choose on the basis of reasons, he was unable to choose, and starved. A better view of these situations, it seems, is that a consideration like that he's hungry is a reason for each alternative, rather than no alternative. If that's correct, then we should say the same thing about the cases I relied on: that I'm expecting a delivery is a reason for each alternative in \{make pizza, make salmon, make pasta\}. But then whether this fact is a reason to make pizza does not vary between this deliberative question and \{make pizza, go out for pizza\}. It's a reason to make pizza in both cases, and so the argument for contrastivism fails. To deny this commits me to saying that Buridan's Ass, whose deliberative question was \{eat the left bale, eat the right bale\}, was correct that he had no reason for either option. 
In fact this is exactly what I want to say about Buridan's Ass, if we assume that the deliberative question he faced was indeed feat the left bale, eat the right bale\}. I say this for the reasons appealed to above: that he's hungry does not distinguish between these two options, and so it wouldn't be intelligible to use it as a premise in settling this question, to base his decision on it, and so on. As a kind of error theory, I suggest that one reason this may sound implausible is because we implicitly assume that the deliberative question he actually faced was \{eat the left bale, eat the right bale, eat neither bale\}; after all, this last option is in fact the one he carried out (whether he chose it or not). Given this deliberative question, that he's hungry is an intelligible premise to use. In particular, it counts (increasingly strongly, as time goes on) against eating neither bale. So if we have in mind this deliberative question, then it is no surprise that this fact seems to be an intelligible premise to use in deliberation. ${ }^{26}$

Importantly, even though I deny both that the fact that he's hungry is a reason for eating the left bale and that it's a reason for eating the right bale, it doesn't follow that he can't make a rational decision in favor of one of these options. This will just amount to a case of non-reasoned choice, or "picking". Quite generally we should be willing to accept the possibility of this kind of rational decision, since we often have to choose in the absence of reasons. ${ }^{27}$ So the mistake the donkey made wasn't in assessing what his reasons were, but either in his not recognizing the strong reasons against one of his alternatives, or in not recognizing the importance of picking (or both). Further, as we saw above, the appropriate deliberative question for an agent to use in deliberation or for us to use in ascribing reasons to the agent need not be completely up to the agent, and in particular to what alternatives the agent happens to be considering.

\section{$5 \quad$ Against a Disunified View of Reasons}

The phenomenon to be explained is that the considerations it is intelligible to use as premises in reasoning about whether to $A$, and thus by the Deliberative Constraint, the reasons for or against doing $A$, can vary depending on the particular deliberative question

\footnotetext{
${ }^{26}$ In fact in Snedegar (2014) and (20I7) I argue that even in the three option case, that he's hungry is not a reason for the donkey to eat the left bale (similarly for the right bale) and point out several ways to mitigate the counterintuitiveness. For example, the fact is a reason against eating neither bale, but not a reason against either of the other options. Further, if I'm right that this fact is not a reason relative to the two member set, holding that it is a reason for each relative to the three member set implies that adding a bad alternative can introduce new reasons in favor of existing alternatives, which is at least prima facie implausible. Finally, one important kind of consideration that supports denying that this fact is a reason to eat the left bale relative to \{eat the left bale, eat the right bale\}, namely, that it isn't an intelligible basis for settling the question in favor of eating the left bale, seems to apply to the three-option case, as well.

${ }^{27}$ For classic discussion, see Ullmann-Margalit and Morgenbesser (1977), and for more recent discussion see Stone (2014).
} 
at issue, illustrated with a pair of cases of partial planning. Both of the relevant deliberative questions have $A$ as a possible answer, but the reasons to $A$ given one deliberative question differ from the reasons to $A$ relative to a different deliberative question. Contrastivism offers a straightforward explanation: the reasons involved are relativized to deliberative questions, so it's no surprise that they can vary with the deliberative questions.

If this argument is sound, then at least some reasons - those involved in partial planning - are contrastive. This is a significant result about the metaphysics of reasons, since it is not widely held that reason relations include an argument place for a deliberative question, or set of alternatives. ${ }^{28}$ But this does not get us all the way to full-blown contrastivism about reasons, which holds that all reasons are contrastive. It is consistent with my argument that only the reasons which are used in partial planning are contrastive. In this section I'll just note some reasons to resist this sort of hybrid-or, less charitably, disunified-view of reasons, according to which some are contrastive and some aren't.

Beyond familiar highly general, and highly defeasible, considerations in favor of unified theories, there is pressure to give a unified account of reasons, in particular. This is because two important things we do with reasons are combine them and weigh them against each other. It is difficult to say anything very precise here, since precise accounts of how reasons combine and compete are hard to come by. 29 But on the face of it, it is difficult to see how a non-contrastive reason could combine or compete with a contrastive one. The outcome of the combining and competing of reasons is some verdict about what the agent has most reason to do, or what she ought to do. If there are both contrastive and non-contrastive reasons involved in the combining and competing, we need to say whether this 'most reason' or 'ought' verdict is contrastive or non-contrastive- that is whether it is a verdict about what you ought to do simpliciter or only relative to a given set of alternatives. Since some of the reasons in the competition were reasons simpliciter, there's some pressure to say the former, but since some were reasons only relative to a given set of alternatives, there's some pressure to say the latter. If all reasons were contrastive (or all were non-contrastive), then at least prima facie, this important part of normative theory would seem more manageable.

More concretely, I have argued against this kind of disunified view of reasons on the basis of linguistic considerations. 30 If this view were true, then the word 'reason' as used to ascribe normative reasons would be ambiguous: sometimes it would refer to contrastive reasons and sometimes it would refer to non-contrastive reasons. But 'reason' fails a well-known test for ambiguity called coordination across conjunction, or conjunction

\footnotetext{
${ }^{28}$ One exception, in addition to those who explicitly endorse contrastivism, is Skorupski (2010).

${ }^{29} \mathrm{~A}$ recent attempt is Horty (2012). It is important for his view that reasons are all the same kind of thingnamely, the premises of defaults, with the same kind of structure - for the kinds of reasons I mention in the main text.

${ }^{30}$ See Snedegar (2013) and (2017), Chapter 2.
} 
reduction. Contrast the oddity of 'The colors and the feathers are light' with the totally natural 'That you sprained your ankle is a reason to wear your brace and to lift weights rather than run'.3 The first is odd because 'light' is ambiguous between a weight sense and a color sense, but the sentence only has one occurrence of 'light', which forces us to try to give it a univocal reading. That there's no similar oddness in the second sentence suggests that 'reason' is not ambiguous between a contrastive sense and a non-contrastive sense.

These arguments against the disunified view are not decisive. But they do put pressure on us to try to give a unified account. If the main argument of this paper is sound, the way to do this is to give a unified contrastive account. In other work, I have shown how to understand apparently non-contrastive reasons as contrastive, so I will not rehearse those accounts here. 32

\section{Conclusion}

I began the paper by mentioning some direct intuitive support for contrastivism. The fact that I'm expecting a delivery is a reason to make pizza rather than go out for pizza, but not a reason to make pizza rather than make pasta. This data suggest that reasons are contrastive. The argument of this paper offers an explanation for why reasons are contrastive: it's because they have to be intelligible premises to use in deliberation, and what counts as an intelligible premise to use in deliberating about whether to $A$ can depend on the particular deliberative question at issue.

Department of Philosophy

University of St Andrews

\section{References}

Bratman, M. (1987). Intention, Plans, and Practical Reason. Cambridge: Harvard University Press.

Cariani, F. (2013). “Ought' and resolution semantics'. Nô̂s, 47(3): 534-558.

Finlay. S. (2014). Confusion of Tongues. Oxford: Oxford University Press.

Finlay, S. and Snedegar, J. (2014). 'One ought too many'. Philosophy and Phenomenological Research, 89(I): IO2-I24.

${ }^{31}$ The first sentence is Sennet's (2016) example, in his helpful discussion of this test for ambiguity. See Schaffer (2007) for use of this argument in defending contrastivism about knowledge.

${ }^{2}$ See especially Snedegar (2013) and (2017). 
Friedman, J. (forthcoming). 'Inquiry and belief'. Forthcoming in Noûs.

--- (2013). 'Question-directed attitudes'. Philosophical Perspectives, 27: I45-I74.

Gregory, A. (2016). 'Normative reasons as good bases'. Philosophical Studies, 173: 2291-23IO.

Groenendijk, J. and Stokhof, M. (I997). 'Questions'. In van Benthem and ter Meulen (eds.), Handbook of Logic and Language, London: Elsevier Science Publishers, pp. IO55'II24.

Hamblin, C. (1958). 'Questions'. Australasian fournal of Philosophy, 36: 159-168.

Hieronymi, P. (2013). 'The use of reasons in thought (and the use of earmarks in arguments)'. Ethics, I24(I): II4-I27.

--- (2005). 'The wrong kind of reason'. The fournal of Philosophy, IO2(9): 437-457.

Horty, J. (2012). Reasons as Defaults. Oxford: Oxford University Press.

Jeffery, R. (1965). The Logic of Decision. Chicago: University of Chicago Press.

Jordan, A. (2014). 'Whole-hearted motivation and relevant alternatives: a problem for the contrastivist account of moral reasons'. Ethical Theory and Moral Practice, I7 (5): 835-845.

Korsgaard, C. (I986). 'Skepticism about practical reason'. Fournal of Philosophy, 83(I): 5-25.

Lin, H. (2014). 'On the regress problem of deciding how to decide'. Synthese, r9r: 661-670.

Raz, J. (I975/1999). Practical Reason and Norms. Oxford: Oxford University Press.

Resnik, M. (I987). Choices. Minneapolis: University of Minnesota Press.

Roberts, C. (2012). 'Information structure in discourse: towards an integrated formal theory of pragmatics'. Semantics and Pragmatics, 5: I-69.

Rooth, M. (I992). 'A theory of focus interpretation'. Natural Language Semantics, I: 75-II6.

Ross, W.D. (I930). The Right and the Good. Oxford: Oxford University Press.

Schaffer, J. (2008). 'The contrast-sensitivity of knowledge ascriptions'. Social Epistemology, 22(3): $235^{-245}$.

--- (2007). 'Knowing the answer'. Philosophy and Phenomenological Research, $75(2): 383^{-} 403$.

--- (2005). 'Contrastive knowledge'. In Gendler and Hawthorne (eds.), Oxford Studies in Epistemology, Vol. I, Oxford: Oxford University Press, pp. 235-27I.

Schroeder, M. (2007). Slaves of the Passions. Oxford: Oxford University Press. 
Sennet, A. (2016). 'Ambiguity'. The Stanford Encyclopedia of Philosophy, E. Zalta (ed.), Spring 2016 edition.

Setiya, K. (2014). 'What is a reason to act?'. Philosophical Studies, I67(2): 221-235.

Smith, M. (1995). 'Internal reasons'. Philosophy and Phenomenological Research, 55(I): I09-131.

Silverstein, M. (2016). 'Reducing reasons'. Fournal of Ethics and Social Philosophy Iо(I): 1-22.

Sinnott-Armstrong, W. (2008). 'A contrastivist manifesto'. Social Epistemology, 22(3): 257' 270.

--- (2006). Moral Skepticisms. Oxford: Oxford University Press.

--- (2004). 'Classy Pyrrhonism'. In Sinnott-Armstrong (ed.), Pyrrhonian Skepticism, Oxford: Oxford University Press, pp. I88-207.

Smith, H. (I99I). 'Deciding how to decide: Is there a regress problem?'. In M. Bacharach \& S. Hurley (eds.), Foundations of Decision Theory, Oxford: Oxford University Press, pp. 1942I9.

Snedegar, J. (2018). 'Reasons for and reasons against'. Philosophical Studies, I75(3): 725-743.

--- (2017). Contrastive Reasons. Oxford: Oxford University Press.

--- (2014). 'Contrastive reasons and promotion'. Ethics, I25(I): 39-63.33

--- (2013). 'Reason claims and contrastivism about reasons'. Philosophical Studies, I66(2): 23I242.

Stone, P. (2014). 'Non-reasoned decision-making'. Economics and Philosophy, 30: 195-214.

Ullmann-Margalit, E. and Morgenbesser, S. (1977). 'Picking and choosing'. Social Research, 44(4): $757^{-7} 785$.

Way, J. (20I7). 'Reasons as premises of good reasoning'. Pacific Philosophical 2uarterly, 98(2): $25 \mathrm{I}^{-2} 27 \mathrm{O}$.

Way, J. and Whiting, D. (2016). 'Reasons and guidance (or, surprise parties and ice cream)'. Analytic Philosophy, 57(3): 214-235.

Wedgwood, R. (2017). 'The predicament of choice'. In R. Shafer-Landau (ed.), Oxford Studies in Metaethics, Vol. I2, Oxford University Press, pp. 294-313.

--- (2015). 'The pitfalls of reasons'. Philosophical Issues, 25: 123-I43.

Williams, B. (I98I). 'Internal and external reasons'. In B. Williams, Moral Luck. Cambridge: Cambridge University Press, pp. IOI-II3. 